\title{
Digital Media Narratives at the Era of Postmodernity: Theatricalization of Politics and Hybrid War
}

\author{
Oksana Lychkovska \\ ORCID: 00oo-0001-9694-4353• ResearcherID: U-3691-2017
}

Odessa I.I. Mechnikov National University, Sociology Department

Received 31 October 2017 • Revised 10 November $2017 \cdot$ Accepted 17 November 2017

\begin{abstract}
Our contribution deals with specific character of contemporary hybrid war represented in digital media. The main element of actual political performances is such ambivalent narrative construction like narratives of crisis reflecting political postmodernism in media spheres. Actual political narrative encompasses all crucial components of postmodern ideology: relativity of truth, truth and lies are defunct as antipodes, when reality is shaping itself as fiction, factchecking of breaking news is absent as far as its bare necessity is arguable. The Ukrainian case, "the Crimea issue" and Russian-Ukrainian hybrid war is one of such illustrative example of theatricalization of politics which can have rather crucial effects. Sociological content-analysis of Ukrainian and Russian media narratives concerned with "the Crimea issue" helped to reveal principal components of information hybrid war that took place in traditional and digital media: hidden mechanisms of political confrontation, new "soft power" as a kind of misinformation creating the phenomena of dissociated consciousness and controlled personality.
\end{abstract}

Keywords: digital narratives, hybrid information war, theatricalization, the Crimea issue.

\section{Introduction}

The main element of actual political performances is creation of ambivalent narrative constructions such a narrative of crisis which reflects political postmodernism in public and media spheres.

Basically, throughout the 20th century, society has passed, at least, through three systemic crises. The first - from 1905 to 1917 - was a crisis of those times European system. The second - from the late 20's to the early 30's - that was a crisis of capitalism and of the world security system. The third crisis swept through the mid-1970s and became the industrial society crisis that had already exhausted itself. Every civilization crisis societies been passing has its own context and content. Crises of the 2oth century were connected: first of all, with the exhaustion of the potentials and drives of the industrial society, its economy, and the mechanisms of political representation as well as foreign policy institutions regulating the nations' interactions on the world arena. The rest of the components of these crises, such as the decline of empires, even added new sharpness to the main crisis causing factor.

The 1970s opened the chapter of post-industrial society, neo-liberalism, globalization and the gradual movement toward postmodernism. The withdrawal of world communism and the

(C) Authors. Terms and conditions of Creative Commons Attribution 4.0 International (CC BY 4.0) apply. Correspondence: Oksana Lychkovska, Sociology Department of Odessa I.I. Mechnikov National University, 24/26 Frantsuzski blv., 65058 Odessa, Ukraine. E-mail: oksanalychkovska@gmail.com. 
end of the ideological struggle gave impetus to the global proliferation of postmodernism as a cultural and political outlook and the formation of appropriate political regulators on its basis. Postmodernism has seemed like the time of fatigue from Progress. The Western elites have done away with their passion for Western values. There came the realm of relativism and faith in relativity of everything around - both life and politics. Taboos, restraints and traditional beliefs were discarded. The eclecticism and ambivalence prevailed both in the approaches to the individual and to social development.

- Political performances are narratives of crisis reflecting political postmodernism.

- Information hybrid war engender soft power influenced consciousness and deformed personality.

- Russian hybrid war technology is a typical postmodernist effective rhetorical method of mixing and amplifying.

- Ukrainian information war technology is less effective "unambiguous and unbiased" reporting of reality.

Actual political narrative encompasses all crucial components of postmodern ideology: relativity of truth; truths and lies are defunct as antipodes, reality takes shape in fiction, fact-checking of breaking news is lacking as far as its necessary is arguable. Thus, the boundaries between law and lawlessness, between sovereignty and interference in internal affairs, between war and peace, reality and fiction began to dissolve. Situations of postmodern in politics concede whether the same political actors are combatants, arbiters and moderators of peaceful settlement.

We have entered the era of world disorder, and it feels like not only in the terrorist attacks' increasing that swept the EU; not only in an enormous number of refugees, - but also in the centrifugal trend launched by Brexit; but also the intensification of the anti-liberal separatist movements in the countries of the Old Europe and the rising nationalism in the countries of the New Europe.

New mechanisms of confrontation in the post-modern era are using of principal components of information hybrid war that had been caught by traditional and digital media, hidden mechanisms of political confrontation, new "soft power" as misinformation creating the phenomena of dissociated consciousness and controlled personality. The Ukrainian case, "the Crimea issue" and Russian-Ukrainian hybrid war is one of the illustrative examples of theatrical rather than crucial effects in politics.

\section{Theoretical discussion}

So, our contribution deals with specific character of contemporary hybrid war represented in digital media. In order to understand how exactly these components are functioning, it is good to recall some classical theories of mass media mechanics.

Accordingly, that recollection allows us to mention the main normative approaches to media, historically presented, of course, by the press (Siebert, Peterson and Schramm, 1956). The oldest one is the authoritarian theory that arose in the authoritarian "climate" of the late Renaissance, simultaneously with the birth of book-printing. The authorities used the press to inform the people not only about what they'd permitted as acceptable in communications, moreover, to explain, what kind of policies the people should support. In contrast, the libertarian theory, originated in the 17th century, but fully developed only in the 18th and 19th centuries, stated that a man to be free in his opinions concerning the state. Mass media, therefore, are not an instrument of the government, but the form of facts and arguments' presentation on the basis of which any people can monitor the government and express their own opinion about politics. In the twentieth century, libertarianism was transformed into the theory of "social responsibility". The presence of a lot of minor media, representing different political views to 
user's choice, ceased to be typical. As in the old times, media still is being handled by limited number of people, who are not the governors, the owners of media. Those who own and operate the media, nowadays decide what people, facts or versions of facts could be presented to the public. That type of business, according to the "theory of social responsibility" generates the belief that the authorities and monopolistic position of media makes them to be socially responsible and to ensure that all parties are fairly represented and consequently, the public has enough information to form their own opinions. And, finally, it was a communist theory, in other words, the authoritarian theory, brought to life by the cold and information war, needing to support and to legitimize one party and one point of view of one leader, found its place in a strictly totalitarian form. Although, since the publication of the book of Fred Seaton Siebert, Theodore Peterson and Wilbur Schramm, the geopolitical configuration of the world has undergone significant changes, nevertheless, all 4 media theories still have been reviving and finding their place in the modern world.

We had identified four main models modern basic interpretations of the social media mission, based on foreign and domestic sources. The first model of professional media mission can be provisionally called "the fourth power model". The journalistic corporation is regarded here as an independent and relatively autonomous social institution involved in the management of society, whose members perform certain functions within the framework of checks and balances between all branches of power. In the former post-Soviet and post-communist countries, the metaphor of the "fourth power" is often obtaining a literal meaning when the media is viewed either as a direct partner of state power, or as a "counterweight", a weapon against it. This reflects, in the final analysis, the underdevelopment of the institutions of power and civil society and the lack of a kind of "social contract" between them.

The second model - the model of social engagement of journalism - considers media as an instrument for protecting the civil rights of individuals or social groups, a means of expressing the interests of different structural links in civil society. That is, various social nongovernmental organizations and volunteer movements, with the help of information provided by the media, who are aware of their interests, and through, are able to control the power and ultimately ensure the realization of their rights and interests.

The third model is the information model itself, based on the premise that the main function of the media is to inform without evaluation. Thus, so-called, "objective journalism", provides the reliable reports from the scene without author's opinions and assessments. However, it should be noted, that this model is quite difficult to implement in practice, as far as any social communication is already a latent assessment, as a matter of fact, social communication, by the easy hand of Jürgen Habermas in his "Theory of Communicative Action" is considered as not "true", but "correct", that is, corresponding "the rules", adopted in a certain society or community. On the other hand - when casting the audience, the actual information passes through a set of evaluative filters in the minds of recipients, who often ignore information not relevant to their personal beliefs.

And, finally, the fourth model is "media as an intermediary". According to this model, the media represent a "platform" at which a permanent public dialogue is organized and maintained with the aim of achieving a balance of power in society. Such a model is more likely to be inherent in new, social media, involving interactivity and a lively participation in the communicative process.

Summing up the various media concepts and models, I would like to dwell on the theoretical grounds that characterize the power regimes in modern society and the place of media technologies in them.

Power as domination. In this case, it deals with not only the ownership of symbolic capital and influence on the audience's minds, but also with the struggling "physical" human 
presence. Thus, the physical presence of the audience is necessary for reproduction of the status of the media. It is a matter of such a traditional and influential intermediary as television. The power of television most visibly manifests itself as domination, manifests inequalities and generates preferences' structures. Television broadcasts the main social discourse, having a kind of monopoly on the formation of public opinion. This was, particularly mentioned in 1996 by P. Bourdieu in his famous work (Pierre Bourdieu, 1996). "Interpreted actions" are beginning to be implemented in reality, and that allows us to talk about a certain "programming" of reality. The inner side of such domination is the diminution of trust in television, (they are watching, but they do not trust). The rates of confidence in television in Ukraine do not exceed 30\%.

The power of media as a social order. That way, electronic media become a kind of "influential and final institution of socialization", especially in a situation where traditional institutions of socialization, such as family and school, lose their significance. E-media are legitimized as expert systems representing the views of specialists or reporting to their own correspondents, as well as "moral referees", practiced by various TV shows. The social order can also be interpreted here as "the rating of social meanings". With the help of traditional media, "protective codes of order" produced by society, any incorrect decoding is being blocked, or its existence in interpretation conventions, could be expressed as generally accepted and competitive projects of reality.

The power of media as communication, understood as a of total, embracing, and ubiquitous practice: in this case, the power of words becomes more vulnerable, while the status of visual images is directly associated with reality and plausibility. At the beginning of the 2000s, we gloated on "the omnipresent media" that cleverly entered our lives by exploiting our personal choices, by changing the structures of power, but also the configuration of perception, interactions with people and institutions (Featherstone, 2009, pp. 1-22).

Ontological or technical power of media is revealed in the theories of Lash and Humbrecht. Thus, Lach (2007: 55-78) proposes a new conception of the "post-hegemony" of the media, which no longer representing simple symbolic domination, or legitimized power, but "the politics of intensity". This was firstly defined as transition from the "epistemological regime" of power to its "ontological regime". The first type of "regime" is realized as the reproduction of the symbolic order through the speech, through the predicative properties of the language defining the object in the set of its attributes. Power in ontological regime manifests itself at the level of existence and facticity in the Heideggerian sense. Second type, is about the mutation of power, which ceases to be "over" domination and becomes "inner" domination. Power as the might and the force generates all that exists in real world daily - in everyday practices of language, bodies, objects, in the permanent production of differences, rather than in reproduction of the symbolic dominant. Third, there is the general shift of norms towards factual information in the political process. And, finally, the extensive regime of the representation of social relations integrated into symbolic representations transformed into an intensive regime of communications legitimizing performativity, that is to say, automatically to everything that is in its orbit (Lash, 2007: 56-68). Thus, we can say that an attempt to differentiate and oppose epistemology and the ontology of domination appears in the sociological theoretical discourse. It is a question of "catching up on reality", or discovering its traces in the multi-layered and mediatized spaces of human life, of reaching what is not expressed, but determining behind the scenes the choices and actions of daily life. Technical power - and more broadly - material power - is manifested even in the usual context, which, apart from meaning, also possesses "material objectivity", and physically influences our body by communicating to its rhythms, sonic and visual fluctuations and realizing, accordingly to the metaphor of Gumbrecht (2006: 110), "the lightest touch of the real world", offering us real contacts with the reality, "sensual and intellectual pleasure". And this is extending other groups of machines and equipment - objects, technology, visual environment, everything you feel, everything you taste. In other words, Gumbrecht (2006: 111) insists on a new power - "an effect 
of presence", achieved through the physical presence of objects (the text, the voice, colours on canvas, and the game of sports). It is not a question of reducing the effect of meaning, but of showing this power coexisting with it.

So, summarizing the main sources of media power in modern society, it seems logical to stress the following: creating a new reality of authority, decentralizing power and thereby weakening it, reducing the trust in power by various means of exposures and journalistic investigations, and finally, a kind of deconstruction of ideologies and a critics the position of journalists opposite to any authority. All of the above, therefore, are the models indicating the changes that have occurred in society and caused a two-way process - the mediazation of politics and politicization of the media.

\section{Method and empirical database}

Thus, the analysis of the newly emerging armed conflicts, hybrid wars and new information wars that we can observe today in Eastern Europe, in particular between Ukraine and Russia, allows us to compare the types of journalism in these countries and note the fact that most media of modern Russia is drawn towards to the authoritarian model of media with the interspersing of strongly totalitarian technologies to protect pro-government opinions and legitimize one leader, while Ukrainian media still try to stay within the framework of libertarian models of social responsibility without imposing predetermined propaganda techniques, which, incidentally, has drawn criticism from the part of the population and from experts, as well as statements that the lack of "hard" information policy in Ukraine, provoked its defeat in the information war with Russia.

Sociological content-analysis of Ukrainian and Russian media narratives concerned "the Crimea issue" enabled to reveal principal components of such informational hybrid war that took place in traditional and digital media.

The empirical database of our research we chose two Internet journals: the Ukrainian one - "Ukrainian Truth" (Ukrainskaya Pravda and the Russian - Vesti.RU). The choice of these sources was determined by following factors: the high rating of publications and relevance, that is, the presence in them of a significant number of articles reflecting the issues of interest to us. The time period of the study was 2 months - March and April 2014, which was the period of the annexation of the Crimea.

Social categories of narrative analyzing such as "agenda settings", "types of content's general modality", "presence/absence of imperative modality", "special visual ways of influence", "character of conflict", "heroes/committers of conflict" permitted us to construct and compare two opposite models of postmodern hybrid information wars: authoritarian and libertarian ones accordingly to "authoritarian and libertarian" media conceptions.

\section{Results}

To conclude the analysis, we have identified significant differences in the way that events were presented. The first issue, attracted our attention was evaluation type concerning the same events. The Ukrainian journal regards events on the peninsula in mostly negative way (58.6\%), at the same time; the Russian journal sees the situation differently: in 6 from 10 publications have positive or neutral characteristics of the events. 
O. Lychkovska - Digital Media Narratives and the Era of Postmodernity ...

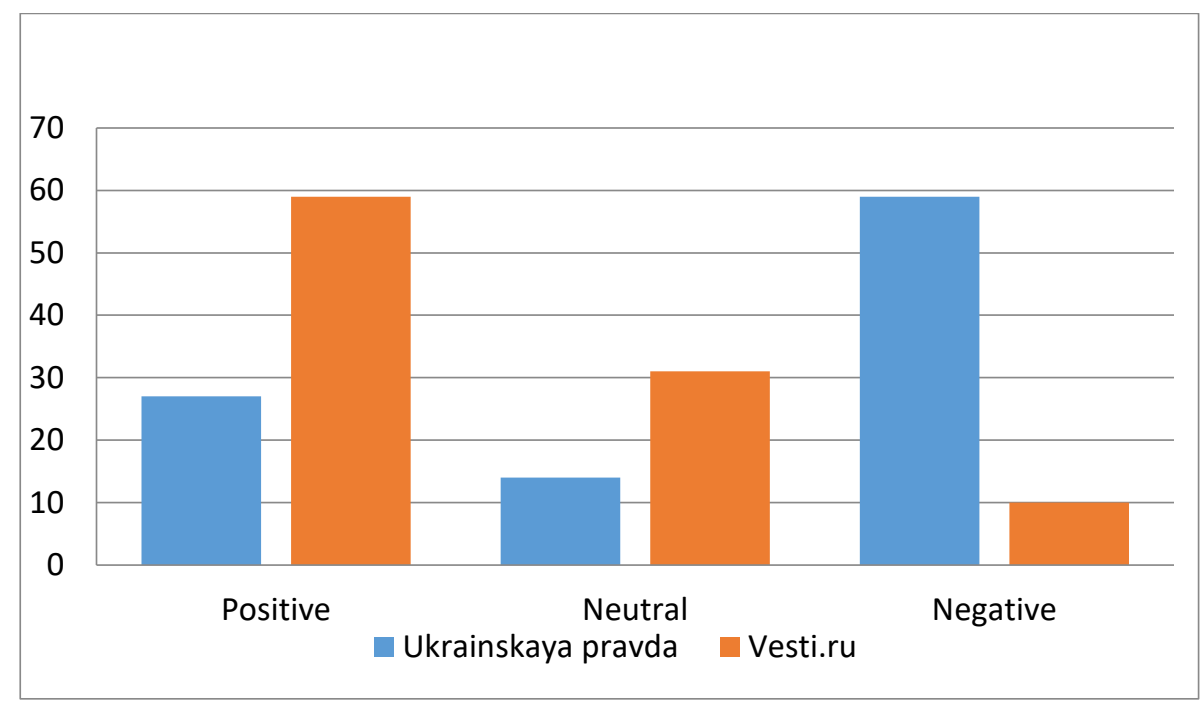

Figure 1. Affective character of information

Quite interesting and sometimes unexpected results have been revealed concerning "factors" of real conflict events. In addition to the fact that the Ukrainian journal was accusing the Russian side of the aggravation of the situation on the peninsula, we have found a rather interesting information technology, which was used by Russian media in question. The Russian journal suggests an interpretation according to which the local population of the peninsula are the originators of the conflict in the Crimea (55.1\%), as like as people whose origin is hard to determine - 24.1\%. At the same time, the Russian side has been presented as "rescuers" of the local population from illegal actions of the Ukrainian authorities.

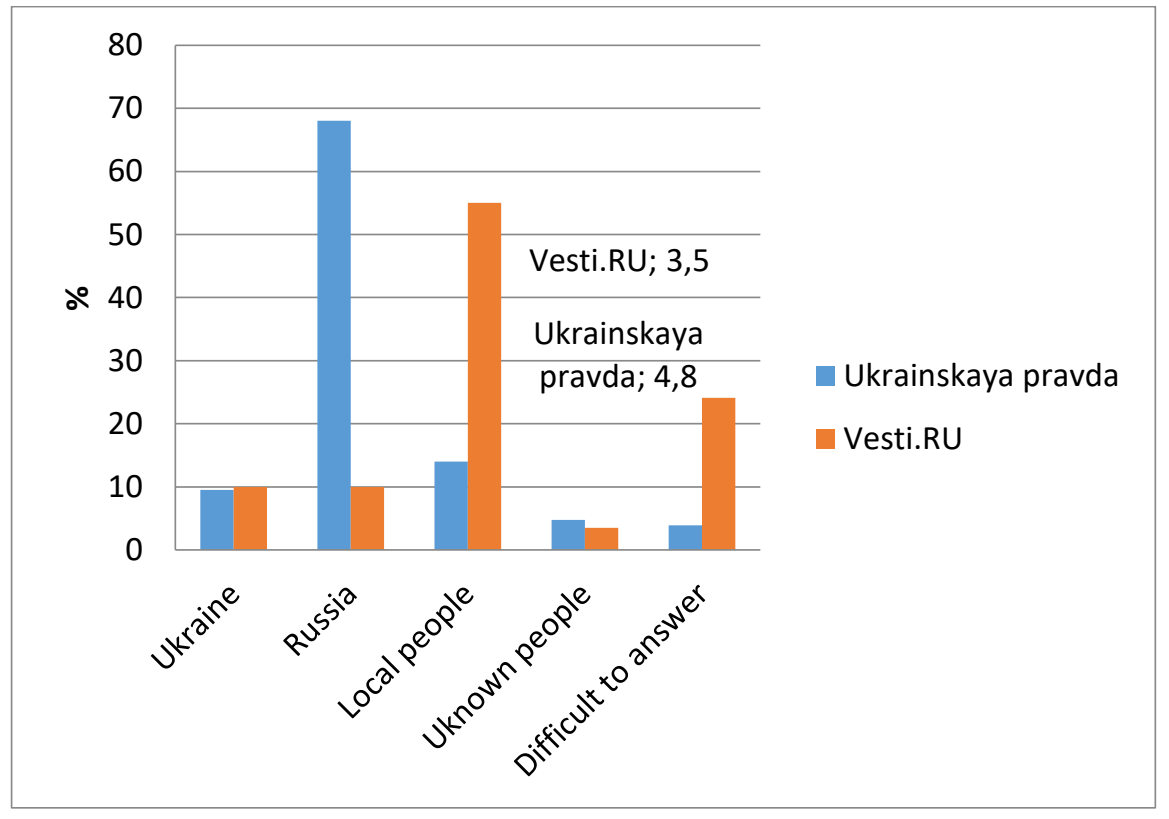

Figure 2. Heroes/commiters of conflict

The analysis of correlations between different categories also helped to discover some additional interesting trends. Thus, comparing the categories "heroes/committers of conflict" and 
"affective character of information", we had found two clear scenarios representing two different mise-en-scenes of the same event, which was considered as the "annexation" of a part of sovereign territory from the point of view of international law. In the Russian journal, the main trigger of the conflict is the local population, whose actions were more likely to be assessed as positive ones. That does not allow us to identify the categories of "heroes/committers of conflict" in Russian media discourse, while the Ukrainian side, whose actions are more likely to be assessed as negative, may well be identified with the "culprit of events".

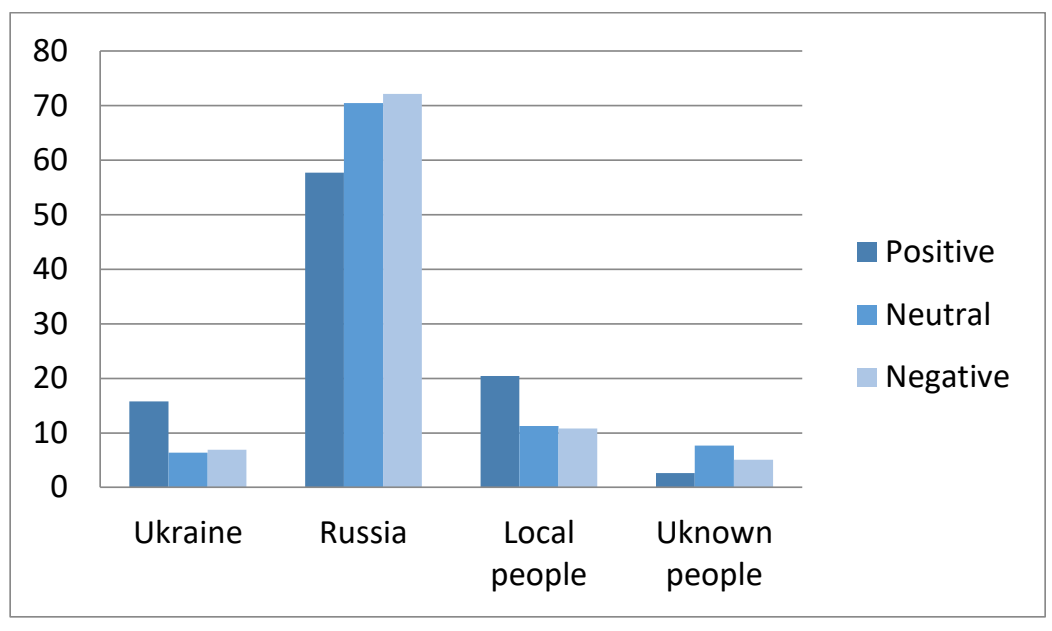

Figure 3. Ukrainskaya Pravda

At the same time, the Russian side as a "cause" of events is presented more neutrally, which gives a clear image of "non-interference", and this image is also strengthened by the idea that "unknown people", those famous "green men" according to Russian Internet journal, were not presented - this was no more than a fiction of Western media. At the same time, for a significant percentage of messages, the affective character cannot be identified, and that allowed us to talk about creating another technology - the "neutrality" of messages. We see here a typical postmodernist rhetorical method of mixing and amplifying, when the introduction of elements of neutrality sets up opportunity to completely change the character of the message, otherwise, "to call black as white is getting rather easy enough" if we dilute the boundaries between the lie and the truth by using neutral judgments and as a result we managed to shift text accents.

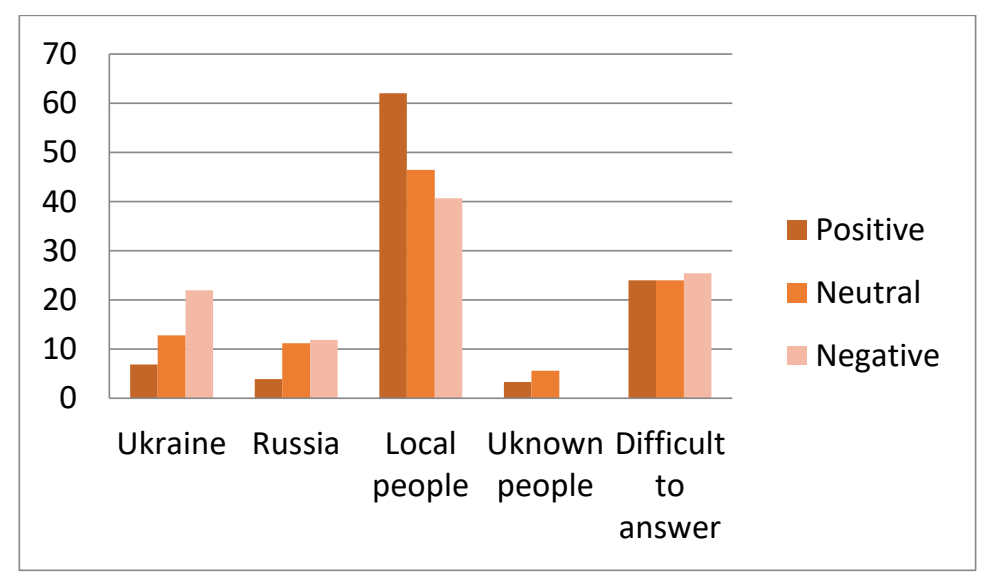

Figure 4. Vesti.RU 
As for as technologies used in the Ukrainian Internet journal, we see a more simple and less effective technology of "unambiguous and unbiased" reporting, when Russia is seen as the main cause of the conflict on the Crimean peninsula, the local population is practically eliminated from the conflict, as like the Ukrainians. At the same time, the emphasis on the presence of "unknown people" is presented more unambiguously.

\section{Conclusion}

So, why does such a strategy seem to us some less effective? It's dealing with how information appears, in other words, what might be a force, becomes a weakness. I'm saying about the desire of Ukrainian media to function within the framework of the "libertarian" model of media, that is, to present the most balanced and most neutral image without becoming a mouthpiece of either the state or any of the parties. The basis for putting forward this hypothesis is the existence of a significant number of neutral judgments, an attempt to balance the interpretation that might be a strong point of Ukrainian media in the situation of sustainable development of the country, but in the situation of crisis and hybrid war, we state that the "libertarian" model is not adapted or much little adapted for information warfare, which causes the loss of information campaigns of Ukraine in comparison with Russia, even in the situation of an explicit and unambiguous geopolitical conflict, such as the "annexation of the Crimea". At the same time, the "postmodern technology of striking borders" becomes more effective, and the lack of free media, that is, the adherence to the "authoritarian model" does not contradict, and even enhances the influence of this technology.

\section{References}

Bourdieu, P. (1996). Sur la télévision. Paris: Liber-Raisons d'agir.

Featherstone, M. (2009). Ubiquitous media: An introduction. Theory, Culture \& Society, 26(2-3), 1-22.

Гумбрехт, Х. У. (2006). Производство присутствия: Чего не может передать значение [Presence production: What value cannot convey?]. Москва: Новое литературное обозрение.

Lash, S. (2007). Power after hegemony: Cultural studies in mutation theory. Culture \& Society, 24, 55-78.

Siebert, F. S., Peterson, Th., \& Schramm, W. (1956). Four Theories of the press: The authoritarian, libertarian, social responsibility, and Soviet communist concepts of what the press should be and do. Urbana: University of Illinois Press. 